\title{
Habitat use and diel activity pattern of the Tibetan Snowcock (Tetraogallus tibetanus): a case study using camera traps for surveying high-elevation bird species
}

Gai Luo ${ }^{1}$, Chuangming Yang ${ }^{1,2}$, Huaming Zhou ${ }^{2}$, Michael Seitz ${ }^{1}$, Yongjie Wu ${ }^{1 *}$ and Jianghong Ran ${ }^{* *}$

\begin{abstract}
Background: Global climate change has had significant effects on animal distribution and population dynamics in mid-latitude alpine areas, but we know little about the basic ecology of high-altitude species due to the difficulties of conducting field research in the harsh climate and habitat present at high elevations. The Tibetan Snowcock (Tetraogallus tibetanus) is a little-known phasianid distributing in alpine areas at extremely high elevations in the mountains surrounding the Tibetan Plateau. Estimating the species occupancy rate and discussing the factors affecting its distribution based on infrared-triggered camera techniques would provide both a baseline to measure the influence of global warming and valuable information on its conservation and ecology.

Methods: We used infrared-triggered cameras to investigate the Tibetan Snowcock on the western slope of Mt. Gongga from June to November 2016. We used the R package "overlap" to visualize its activity pattern, and used an occupancy model to both examine its habitat use as well as to determine the most influential variables affecting its habitat use.

Results: Using 103 camera traps over 9213 camera-days, we recorded 428 instances of Tibetan Snowcock. The diel activity peaks of Tibetan Snowcock occurred during the periods of 8:00-10:00 am and 18:00-20:00 pm. The model estimate of occupancy for Tibetan Snowcock (0.830) was slightly higher than the naïve site occupancy based on camera detections (0.663), indicating a wider use of habitat than the camera traps recorded. Elevation, slope, settlement density, road density, and EVI (enhanced vegetation index) were the most influential variables for its habitat use.

Conclusions: The Tibetan Snowcock is confirmed to be diurnal. This species prefers an environment with a high elevation, gentle slope, and low EVI, apparently facing a trade-off between predator risk, foraging efficiency, and food availability. When human impact was low, there was a positive correlation between the habitat use of the Tibetan Snowcock and both its road and settlement densities. Infrared cameras and proper survey design are valuable for investigating extreme alpine phasianids.
\end{abstract}

Keywords: Activity pattern, Habitat preference, Mt. Gongga, Occupancy model, Tibetan Snowcock

\footnotetext{
*Correspondence: wuyongjie@scu.edu.cn; ranjianghong@scu.edu.cn

${ }^{1}$ Key Laboratory of Bio-Resources and Eco-Environment of Ministry of Education, College of Life Science, Sichuan University, No. 24 South Section 1, Yihuan Road, Chengdu 610065, China

Full list of author information is available at the end of the article
} 


\section{Background}

In recent decades, many environmental changes have occurred in response to global climate change in the mid-latitude alpine regions, including glacier retreat, the spring phenology of local vegetation, and the composition of the plant community (Wookey et al. 2009; Li et al. 2010b; Shen et al. 2015; Ferrarini et al. 2017), all of which have the potential to affect bird populations. Therefore, determining the status of species in these areas is a valuable conservation research priority. Out of 179 species of phasianid, 63 occur in China (Zheng 2005), but most of them are lacking information on basic ecology and distribution. Information for those phasianids distributing in alpine regions is especially lacking, due to the difficulties in conducting field research in their environment. Alpine areas are hard to reach and have extreme climate conditions. Local species are also difficult to observe. Besides global climate change, recent research suggests that many phasianids are also suffering habitat loss due to hunting, livestock use, and disturbance from tourism and traffic (Li et al. 2010a; Srivastava and Dutta 2010; Zhang et al. 2017). Monitoring these alpine species and providing a baseline for the influence of global warming and human disturbance are thus becoming an urgent priority in China (Ding and Zheng 2000; McGowan et al. 2009; Soldatini et al. 2010).

Choosing the proper approach monitoring wildlife is always a challenge in management or conservation (Pollock et al. 2002). The use of infrared-triggered camera traps has increased dramatically in recent years (Garrote et al. 2011; Niedballa et al. 2016). It has been proposed as an effective tool for investigating medium- to large-sized terrestrial vertebrates, and especially for studying and monitoring elusive species (Janecka et al. 2011; Burton et al. 2015; Tan et al. 2017). O'Brien and Kinnaird (2008) reviewed the use of camera traps in bird research and suggested the method was most appropriate for large, ground-dwelling birds. Li et al. (2010a) also suggested cameras were valuable for surveying or monitoring phasianids. So far, we still do not know whether camera traps can perform well in extreme alpine habitats where the temperature varies highly within a single day, and there are no trees or shrubs on which to fix or hide cameras. If camera traps can be effective in this environment, when coupled with proper design they could be a valuable tool for monitoring phasianids in extreme high-elevation areas.

The Tibetan Snowcock (Tetraogallus tibetanus), a typical alpine phasianid, mainly ranges across the QinghaiTibetan Plateau from Pamirs in the west to Mt. Gongga in the east (MacKinnon et al. 2000). It is a Category II National Protected Animal in China, and is listed in CITES Appendix I (www.cites.org) and evaluated as a Least Concern species by the IUCN (www.redli st.org). According to limited descriptions, the Tibetan Snowcock inhabits a zone exceeding $4000 \mathrm{~m}$ in summer, and $3000 \mathrm{~m}$ in winter. Its breeding season begins in mid-May, and as a precocial species the snowcocks normally led to forage on the same day they hatch from their eggs (Zheng 2015). As the species distributes at elevations close to glaciers and the snow line (MacKinnon et al. 2000), it is worried that it may be susceptible to influence by glacial retreat and the coinciding rise in temperature. Global warming has been responsible for the partial melting of glaciers on the Qinghai-Tibetan Plateau (Li et al. 2010b). Previous research suggested that the population size of the Tibetan Snowcock has declined in the 1990s (Soldatini et al. 2010). Unfortunately, due to the difficulties in conducting field work at extremely high elevations and on rocky terrain, its global population size and trends have not been rigorously quantified (del Hoyo et al. 1994).

Due to the potential influence of climate change and the current lack of information on the Tibetan Snowcock's life history and other basic ecology, understanding the species habitat use and diel activity pattern is therefore essential to its conservation (Guisan and Thuiller 2005; Singh and Macdonald 2017). The occupancy model (Mackenzie et al. 2002) is an important way for modelling habitat use, as it explicitly accounts for imperfect detection during surveys, thus enabling analysis of how each different covariate affects it. The assumptions of this model are (1) there is no change in habitat use intensity between surveys, and (2) the detection of the species at a site is independent of detection of the species at any other sites. At the same time, the change in occupancy rates could represent the change in population dynamics between surveys, which is more effective than using relative abundance indices based on trapping efforts, because of the difficulty of standardizing surveys over time and space (O'Brien and Kinnaird 2008). Therefore, estimating the occupancy rate of Tibetan Snowcock provides a baseline of its habitat use and current population status for future research on the influence of global warming.

As a global biological diversity hotspot, the Hengduan Mountain Range is one of the main regions of distribution of the Tibetan Snowcock and other several rare phasianids, including the Chinese Monal (Lophophorus lhuysii), Buff-throated Partridge (Tetraophasis szechenyii) and Blood Pheasant (Ithaginis cruentus) (MacKinnon et al. 2000; Marchese 2015; Wu et al. 2017). This vast, mountainous region is likely to face presently unknown effects from global climate change, including habitat loss for species at high elevations. Mt. Gongga, as the highest mountain within this biological hotspot and an Important Bird Area (IBA Code: CN219), is an ideal place to 
study the high alpine species and the possibility of camera trap use in high-elevation areas.

In this study, we used camera traps to investigate the Tibetan Snowcock on the eastern edge of the QinghaiTibetan Plateau during its post-breeding period to (1) determine the species' diel activity pattern; (2) examine its habitat preference based on the occupancy model; and (3) discuss ways of improving the survey method and future protocol in remote sensing techniques for highelevation species.

\section{Methods}

\section{Study area}

The work was carried out on the western slope of Mt. Gongga $\left(29^{\circ} 01^{\prime}-30^{\circ} 05 \mathrm{~N}, \quad 101^{\circ} 29^{\prime}-102^{\circ} 12^{\prime} \mathrm{E}\right)$, located on the eastern edge of the Qinghai-Tibetan Plateau in Sichuan Province, China. The main peak, Mt. Gongga, is the highest point in the Hengduan Mountains (Fig. 1).
The vertical climatic zonation on the western slope of Mt. Gongga includes a sub-alpine cool temperature zone, an alpine sub-frigid zone, an alpine frigid zone, and a permanent snow zone. The major vegetation types are deciduous forest, conifer-deciduous mixed forest, conifer forest, alpine scrub, alpine meadow, flat or gently sloping rocky areas, and glacier. Mt. Gongga is also one of the most eastern glacial areas in China with five valley glaciers of a length greater than $10 \mathrm{~km}$, including Hailuogou glacier, Mozigou glacier, Yanzigou glacier and Nanmenguangou glacier on the eastern slope, and Gongba glacier on the western slope ( $\mathrm{Li}$ et al. 2010b). Dozens of mountains with elevations over $6000 \mathrm{~m}$ surround the main peak of Mt. Gongga, and together with the glaciers form a magnificent landscape and the environment of the Tibetan Snowcock.

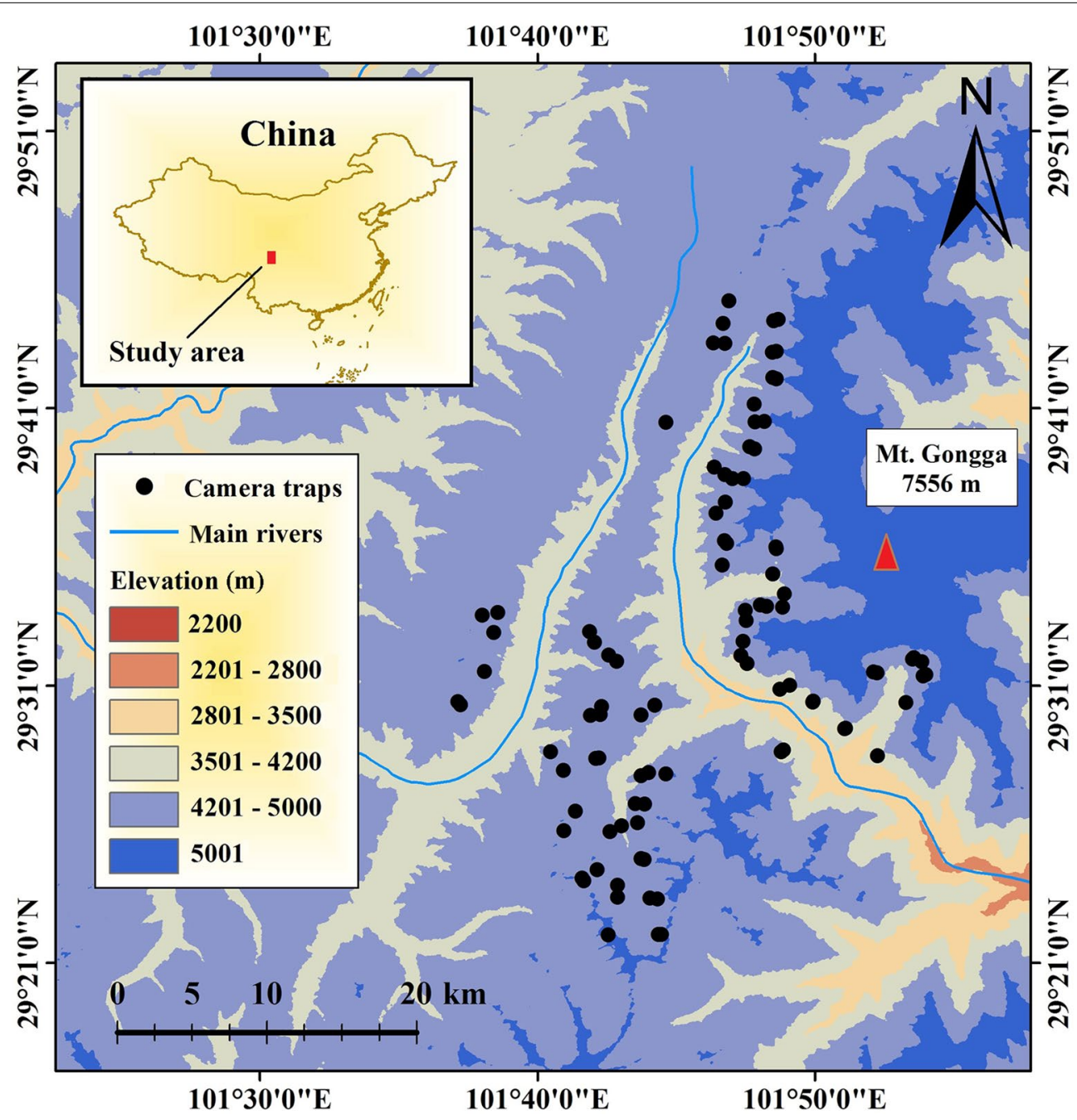

Fig. 1 Locations of camera traps in Mt. Gongga, China 


\section{Field survey}

The survey was carried out from late June to early November 2016 with a survey area around of $650 \mathrm{~km}^{2}$. We divided the survey area into $5 \mathrm{~km} \times 5 \mathrm{~km}$ blocks using geographic information systems (GIS), and two transect trails were established in each block with a distance of at least $1 \mathrm{~km}$ between them. When the transect survey began, trained staff deployed two camera traps (Ltl-6210MG, China) on each transect trail somewhere likely to be used by animals at their own discretion. In total, 103 camera traps were deployed between 3925 and $5084 \mathrm{~m}$ in elevation (Fig. 1). Each camera trap was carefully hidden in a rock pile to prevent animal disturbance. The camera traps were placed $30-40 \mathrm{~cm}$ above ground and set to work $24 \mathrm{~h}$ /day with a two-second delay between consecutive exposures. If any activity triggered the camera, three consecutive photographs followed by a $9 \mathrm{~s}$ video were recorded. We recorded the GPS location, elevation, slope, aspect, and vegetation type at each camera sample site. The beginning date of each camera trap was the date when the camera was deployed. At the end of the survey, the camera traps were tested to confirm that they were still operational; if not, the date on the last photograph was recorded as the last operational date. The time and temperature were recorded automatically by the camera traps and shown on the photographs.

\section{Data analysis}

Camera traps that failed to collect data were first removed from the final dataset. Due to disturbances from curious animals and equipment failures, only 92 camera traps produced data included in our analysis. We defined a detection at a camera trap as one individual photograph of one species during a 30-min period. After importing and marking photographs captured by camera traps in DigiKam 5.3 (www.digikam.org), we extracted information through a process using the R package "camtrapR" (Niedballa et al. 2016). We obtained a relative abundance index by calculating the number of photo-captures obtained for each species within a period of 100 trap days. To understand the diel activity periods of this phasianid, we used the $\mathrm{R}$ package "overlap" to visualize its activity pattern.

To examine the habitat use of the Tibetan Snowcock, we divided the entire monitoring period into consecutive 5-day segments. Then, as described by Mackenzie et al. (2002), we set up a Tibetan Snowcock detection matrix, which would meet the two assumptions of this model as outlined in the introduction. Each element in the matrix represented one segment at one camera trap sampling site. We used 1 to represent that the Tibetan Snowcock was detected in this segment, used $O$ to represent no detection, and used $N A$ to represent data missing. Detection probability of the Tibetan Snowcock was assessed in relation to two detection covariates, and ten site covariates were considered to be potentially influential for its habitat use (Table 1). The elevation, slope, and aspect data were recorded by the field staff. The EVI (enhanced vegetation index) data were acquired from the Geospatial Data Cloud of the Chinese Academy of Sciences (http://www.gscloud.cn). The administration of the Gongga Mountain National Nature Reserve provided the

Table 1 Variables used to estimate the site occupancy rate and detection probability of Tibetan Snowcock in the occupancy model

\begin{tabular}{lll}
\hline Abbreviation & Name & Description \\
\hline Site covariates & & \\
ELE & Elevation & Numeric (range 3925-5084 m) \\
ASP & Aspect & Categorical (E, N, NE, NW, S, SE, SW, W) \\
SLO & Slope & Numeric (range 1.7-48.3 $)$ \\
DTRI & Distance to the nearest river & Numeric (range 30-2749 m) \\
DTRO & Distance to the nearest road & Numeric (range 29-9023 m) \\
DTSE & Distance to the nearest settlement & Numeric (range 1583-15,715 m) \\
RID & River density & Numeric (range 0.084-0.482) \\
ROD & Road density & Numeric (range 0.030-0.207) \\
SED & Settlement density & Numeric (range 0.000-0.143) \\
EVI & Enhanced vegetation index & Numeric (range 0.028-0.301) \\
Detection covariates & & \\
DATE & Date & Numeric (range -5 to 135) \\
LT & Livestock & The average days of each segment away from the second segment (1-5 July) \\
& & Logical (TRUE: livestock photographed in a segment; FALSE: livestock not \\
\hline
\end{tabular}


raw data on rivers, settlements, and roads. Therefore, the other six site variables (distance to the nearest river, distance to the nearest settlement, distance to the nearest road, river density, settlement density, road density) were extracted using geographic information systems (GIS) and the raw data.

Pearson's correlation test was used to identify collinearity between all continuous site covariates (Additional file 1: Table S1). Any combination of covariates with $r>|0.6|$ was considered correlated (Tan et al. 2017). Distance to the nearest road and distance to the nearest settlement were removed, because they were correlated with road density and settlement density respectively. Since road density and settlement density could represent different (lines and points) human impact, we retained these two covariates in the analysis. We also retained elevation and EVI, because the two site covariates should affect the use of habitat in different ways, e.g., physiology versus food richness.

Then, we used the R package "Unmarked" (Fiske et al. 2011) and called on the occupancy model (Mackenzie et al. 2002) to estimate the occupancy rate and detection probability of Tibetan Snowcock. We modelled detection probability $(p)$ by allowing the site covariates to remain constant. The significant contributing detection covariates were retained and used to model habitat use probability in relation to the site covariates (Long et al. 2011; Tan et al. 2017). We used R package "MuMIn" to run and list all the potential models. Akaike's information criterion corrected (AICc) values were then used to rank the occupancy models (Sugiura 1978; Hurvich and Tsai 1991). All models with $\Delta$ AICc $\leq 2$ were considered as competing models. The sum model weight of each covariate in these competing models was used to determine the most influential variables for the habitat use of the Tibetan Snowcock.

\section{Results}

Through data produced by the 92 camera traps used in analysis, our sampling efforts amounted to 9213 cameradays, and the mean sampling duration was 94 days at each site. There were a total of detections of the Tibetan Snowcock resulting in relative abundance index of 4.646 photographs per 100 trap days. The elevation of the lowest site detection was $4118 \mathrm{~m}$, while the highest was $5084 \mathrm{~m}$. Overall, 158 detections contained only one individual Tibetan Snowcock, while 270 detections included at least two individuals. The largest recorded group size was 13 individuals (Fig. 2). The diel activity peaks of the Tibetan Snowcock occurred during the periods of 8:00-10:00 am and 18:00-20:00 pm (Fig. 3).

Neither of the two detection covariates (DATE and LT) reached summed model weights of $>0.5$ (Table 2),

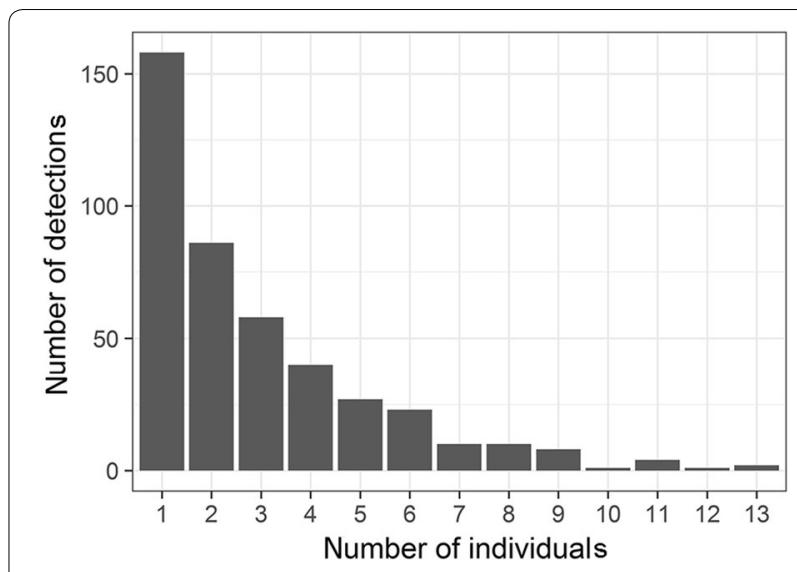

Fig. 2 Number of individuals in detections of Tibetan Snowcock photographed in Mt. Gongga, from June to November 2016

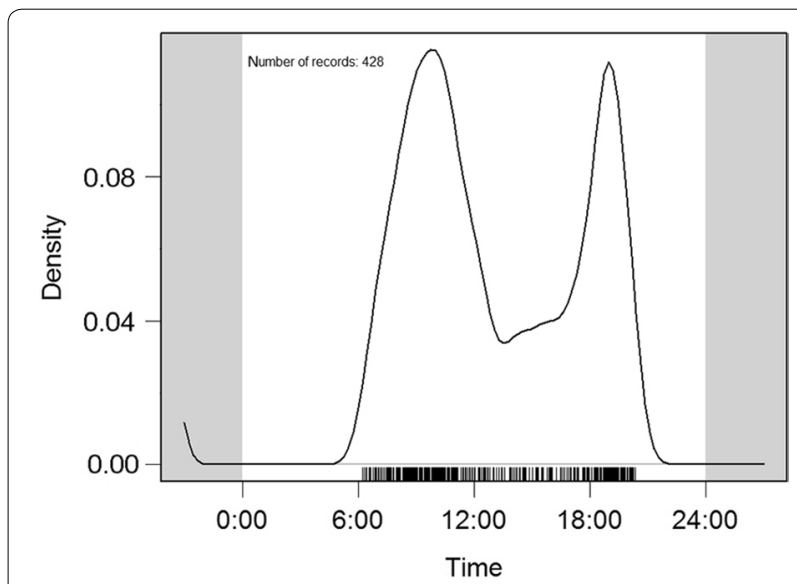

Fig. 3 Diel activity pattern of Tibetan Snowcock from combined data in Mt. Gongga, from June to November 2016

Table 2 Tibetan Snowcock detection probability (p) models

\begin{tabular}{lllll}
\hline Model & $\boldsymbol{\Delta}$ AICc & AICc weight & No. par. & $(\mathbf{- 2 L L )}$ \\
\hline (a) & & & & \\
$p()$. & 0.000 & 0.385 & 2 & -770.245 \\
$p($ LT) & 0.964 & 0.237 & 3 & -769.660 \\
$p$ (DATE) & 1.076 & 0.225 & 3 & -769.716 \\
$p($ LT, DATE) & 1.836 & 0.153 & 4 & -769.005 \\
\hline Detection covariates & & Summed model weights \\
\hline (b) & & & & \\
LT & & 0.263 & \\
DATE & & 0.238 & \\
\hline
\end{tabular}

(a) We list all models, and present AICc weight, number of parameters (No. par.), twice the negative log likelihood (-2LL). (b) Summed model weight of each detection covariates. The key for the covariate codes used is given in Table 1 
Table 3 Tibetan Snowcock occupancy $(\psi)$ models

\begin{tabular}{|c|c|c|c|c|c|}
\hline Model & $\triangle \mathrm{AICc}$ & AICc weight & No. par. & $(-2 L L)$ & $\psi( \pm \mathrm{SE})$ \\
\hline \multicolumn{6}{|l|}{ (a) } \\
\hline$\psi(E V I, E L E, ~ R O D, S E D, S L O)$ & 0.000 & 0.150 & 7 & -753.453 & $0.830( \pm 0.073)$ \\
\hline 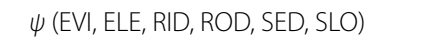 & 0.297 & 0.129 & 8 & -752.405 & $0.826( \pm 0.073)$ \\
\hline$\psi(E L E, R O D, S E D, S L O)$ & 1.152 & 0.084 & 6 & -755.197 & $0.789( \pm 0.072)$ \\
\hline$\psi(E L E, D T R I, ~ R O D, S L O)$ & 1.212 & 0.081 & 6 & -755.231 & $0.765( \pm 0.084)$ \\
\hline 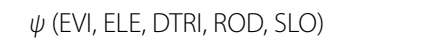 & 1.289 & 0.078 & 7 & -754.098 & $0.932( \pm 0.066)$ \\
\hline$\psi(E V I, E L E, R O D, S L O)$ & 1.417 & 0.074 & 6 & -755.330 & $0.812( \pm 0.098)$ \\
\hline 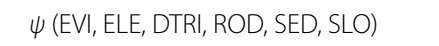 & 1.446 & 0.073 & 8 & -752.980 & $0.837( \pm 0.072)$ \\
\hline$\psi(E L E, D T R I, R O D, S E D, S L O)$ & 1.494 & 0.071 & 7 & -754.200 & $0.799( \pm 0.072)$ \\
\hline$\psi(E L E, R O D, S L O)$ & 1.542 & 0.069 & 5 & -756.534 & $0.761( \pm 0.078)$ \\
\hline$\psi(E L E, R I D, R O D, S E D, S L O)$ & 1.629 & 0.066 & 7 & -754.267 & $0.776( \pm 0.074)$ \\
\hline 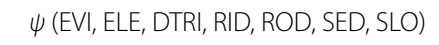 & 1.652 & 0.065 & 9 & -750.859 & $0.819( \pm 0.075)$ \\
\hline$\psi(E L E$, DTRI, RID, ROD, SED, SLO) & 1.828 & 0.060 & 8 & -753.171 & $0.770( \pm 0.074)$ \\
\hline$\psi()$. & 22.413 & - & 2 & -770.245 & $0.707( \pm 0.053)$ \\
\hline Site covariates & & & & & $\begin{array}{l}\text { Summed } \\
\text { model } \\
\text { weights }\end{array}$ \\
\hline \multicolumn{6}{|l|}{ (b) } \\
\hline ELE & & & & & 1.000 \\
\hline SLO & & & & & 1.000 \\
\hline $\mathrm{ROD}$ & & & & & 1.000 \\
\hline SED & & & & & 0.697 \\
\hline $\mathrm{EVI}$ & & & & & 0.569 \\
\hline DTRI & & & & & 0.429 \\
\hline RID & & & & & 0.321 \\
\hline
\end{tabular}

(a) We list all models whose $\triangle \mathrm{AICc} \leq 2$, null model, and present AICc weight, number of parameters (No. par.), twice the negative log likelihood ( $2 \mathrm{LL}$ ) and estimated occupancy rate $(\psi)$. (b) Summed model weight of each site covariates in the equivalent models. The key for the covariate codes used is given in Table 1

indicating that they had no significant effect on detection probability of the Tibetan Snowcock, and detection probability was assumed to be constant. Out of 92 camera traps, 69 recorded Tibetan Snowcock at least once, resulting in a naïve site occupancy of 0.663 . The model with the lowest AICc estimated the occupancy at 0.830 (Table 3), slightly higher than the naïve site occupancy, suggesting that the habitat use of the Tibetan Snowcock was wider than indicated by the camera trap record. Among competing models, elevation, slope, EVI, road density, and settlement density reached summed model weights of $>0.5$, and these covariates were considered as weighted predictors for the habitat use of the Tibetan Snowcock. There was a positive correlation between habitat use and elevation, road density, and settlement density, while habitat use was negatively associated with slope and EVI (Fig. 4).

\section{Discussion}

The detections with an occurrence of at least two individuals totaled 270, indicating the species' tendency for collective activity. Considering the relatively small monitoring range in each sample site, it is possible that the camera trap may photograph only one individual when a group of snowcocks pass by, meaning the 158 detections of one individual may underestimate the group size. Results thus indicate that more traps at each site would be needed to determine the correct group size, as single camera is often unable to capture an entire group of Tibetan Snowcock. According to the results of the diel activity pattern study, we confirmed that Tibetan Snowcock is diurnal, like many other phasianids (O'Brien and Kinnaird 2008; Li et al. 2010a). However, the reason why the two peaks of diel activity occurred specifically during 8:00-10:00 am and 18:00-20:00 pm is not yet known. Usually, phasianids forage in the morning and just before the nightfall, while resting at noon. In high alpine areas lacking trees or shrubs, the temperature would be higher and ultraviolet rays more intense at noon, and thus the 

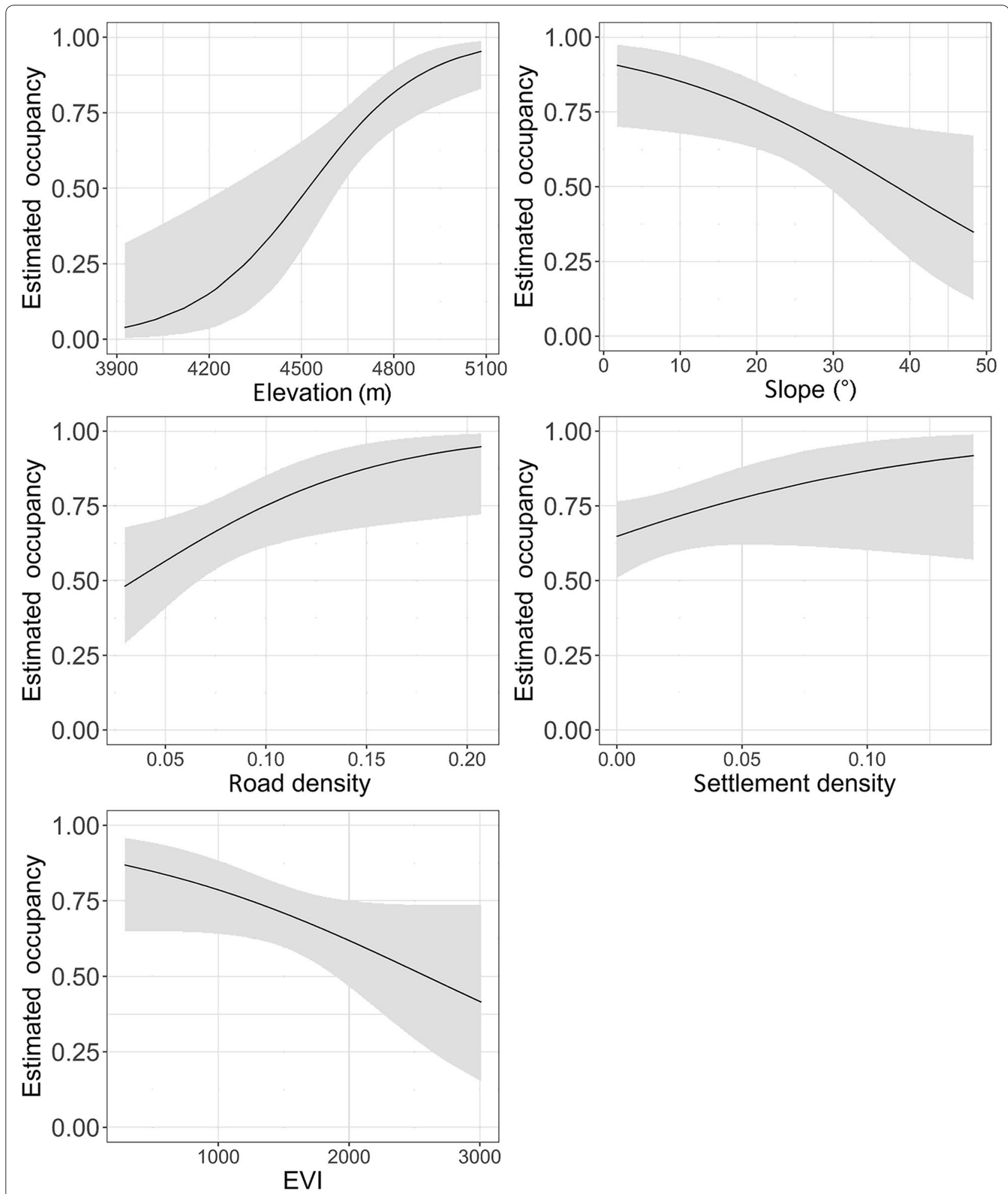

Fig. 4 Correlations between Tibetan Snowcock estimated habitat use probability and site covariates of elevation, slope, road density, settlement density and EVI 
hump-shaped diel activity pattern may help phasianids avoid energy loss and negative effects from intense ultraviolet radiation.

We found that the Tibetan Snowcock prefers an environment with a high elevation, gentle slope, and low EVI. The preference for higher elevation coincides with its known ecology of living close to glaciers and the snow line. However, elevation is usually negatively correlated with vegetation productivity, represented by EVI in this study. Low EVI indicates low vegetation productivity and poor food resources for this strictly herbivorous species (Yan et al. 2010), creating an apparent contradiction between habitat use and the availability of food. Therefore, we infer that there may be a trade-off between predator risk, foraging efficiency, and food availability. Bland and Temple (1990) reported the habitat selection of a small introduced Himalayan Snowcock (TetraogaIlus himalayensis) population in Nevada, USA, and their results suggested that the Himalayan Snowcock would trade higher foraging efficiency and better foraging habitat for lower predation risk during summer. However, when predation risk is lower in winter, the Himalayan Snowcock would revert to using high-efficiency foraging habitats. At higher elevations on Mt. Gongga, seeking food may be more difficult, but the Snowcock's competitors and predators, such as other phasianids and raptors, might be less common. At the same time, a gentler slope indicates a higher foraging efficiency as vegetation is exposed to more solar energy and is easier to access than on a steeper slope. Therefore, the Tibetan Snowcock's preference for a higher-elevation environment with poor food richness may be a tradeoff with decreasing the risk of predation and interspecies food competition. Meanwhile, foraging efficiency increased by choosing habitats with a gentler slope. The results also showed that the habitat use of the Tibetan Snowcock is positively correlated with road density and settlement density. Soldatini et al. (2010) also found that Tibetan Snowcock often foraged in potato fields in Nepal, indicating that human impact provided an advantage for Tibetan Snowcock and influenced the species' distribution. We suggest further research to explore the reasons for the species' apparent preference for habitat near human activity.

Our study also generated some recommendations for the improvement of future survey design and protocol. The highest elevation at which Tibetan Snowcock occurred was $5084 \mathrm{~m}$, reaching the upper limit of the elevation range in which we placed camera traps. The presence of the species at the limit of our study indicates that we need to place additional camera traps at higher-elevation sites. Of the 103 sites sampled in Mt. Gongga, 11 camera traps located at lower elevations did not work and the sites were thus not considered in our analysis. One of the main reasons was disturbance by animals, especially livestock, which trampled on and caused the malfunction of several cameras. Unlike fixed cameras on tree trunks in the forest, careful camouflage is important for cameras placed on the ground in extreme-high alpine areas. False triggers by non-animal events also deleted the memory of the camera with a few days or, in some cases, a few hours, resulting in incomplete monitoring data. Strong winds would falsely trigger camera traps by blowing twigs in front of lens. In extreme high-elevation areas where the cameras are placed directly under the sun, camera traps were also falsely triggered by sunlight. Therefore, staff should be careful to clear out the small area in front of lens and position the lens so as to avoid direct sunlight.

The population size of the Tibetan Snowcock is believed to be large (del Hoyo et al. 1994). However, the species distributes at elevations close to glaciers and the snow line, and faces the rapid retreat of glaciers in the Mt. Gongga region (MacKinnon et al. 2000; Li et al. $2010 \mathrm{~b})$. Due to the small number of existing publications on this species, determining its population dynamics is a difficult task. In this study, we documented the estimated occupancy and altitudinal distribution of the species, which provides a baseline from which to assess the future effects of global warming in a high-altitude area (Soldatini et al. 2010). Along with the employment of remote sensing techniques and suitable survey designs, we believe the occupancy estimates of the Tibetan Snowcock will provide valuable information on the species' population dynamics in future long-term monitoring projects.

\section{Conclusions}

For the first time, we reported the occupancy rate and diel activity pattern of Tibetan Snowcock. We concluded that the distribution of this species exceeded $5000 \mathrm{~m}$ on elevation and it was diurnal. Habitat use of the Tibetan Snowcock is influenced by both natural conditions and human impact in the Qinghai-Tibetan Plateau. Elevation, slope, settlement density, road density, and EVI were the most influential variables affecting its habitat use. The Tibetan Snowcock prefers a higher elevation environment with poorer food richness in order to decrease the risk of predation and interspecific food competition. To increase foraging efficiency in an environment with poor food richness, the Tibetan Snowcock chooses habitats with a gentler slope. Further research is required to explore the reasons why the species' habitat use is correlated with human activity. Along with occupancy estimations, long-term monitoring of the population dynamics of the high alpine species is necessary for future studies. 


\section{Additional file}

Additional file 1: Table S1. Pearson's correlation test for all continuous site covariates.

\section{Authors' contributions}

YW and JR conceived the project. CY and HZ designed the camera trap survey, and collected the field habitat data. GL analyzed the camera trap data. MS revised the manuscript. GL, YW and JR led the writing of the manuscript. All authors read and approved the final manuscript.

\section{Author details}

${ }^{1}$ Key Laboratory of Bio-Resources and Eco-Environment of Ministry of Education, College of Life Science, Sichuan University, No. 24 South Section 1, Yihuan Road, Chengdu 610065, China. ${ }^{2}$ The Administration of the Gongga Mountain National Nature Reserve, Ganzi Tibetan Autonomous Prefecture, Ganzi 626000, China.

\section{Acknowledgements}

We are grateful to all the staff of the Gongga Mountain National Nature Reserve for their support. We thank Sheng Li, Yu Xu, and Cedric Tan for their advice.

\section{Competing interests}

The authors declare that they have no competing interests.

\section{Availability of data and materials}

The datasets generated during our field survey and analyzed in the study are not publicly available owing to the fact that they are part of our field work, but are available from the corresponding author on the basis of a reasonable request. Environmental data used for our occupancy model are available on the public networks of the Geospatial Data Cloud of the Chinese Academy of Sciences (http://www.gscloud.cn/)

\section{Consent for publication}

Not applicable.

\section{Ethics approval and consent to participate}

Not applicable.

\section{Funding}

This work was supported by the National Natural Science Foundation of China (No. 31772478, 31501851) and the Administration of the Gongga Mountain National Nature Reserve.

Received: 22 August 2018 Accepted: 22 January 2019

Published online: 04 February 2019

\section{References}

Bland JD, Temple SA. Effects of predation-risk on habitat use by Himalayan Snowcocks. Oecologia. 1990;82:187-91.

Burton AC, Neilson E, Moreira D, Ladle A, Steenweg R, Fisher JT, Bayne E, Boutin S. Wildlife camera trapping: a review and recommendations for linking surveys to ecological processes. J Appl Ecol. 2015;52:675-85.

del Hoyo J, Elliot A, Sargatal J. Handbook of the birds of the world, New World Vultures to Guineafowl. Barcelona: Lynx Edicions; 1994.

Ding CQ, Zheng GM. The regions of conservation importance for grouse, partridges and pheasants in China. Bird Conserv Int. 2000;10:319-30.

Ferrarini A, Alatalo JM, Gustin M. Climate change will seriously impact bird species dwelling above the treeline: a prospective study for the Italian Alps. Sci Total Environ. 2017;590:686-94.

Fiske I, Chandler R, Leeuw JD, Zeileis A. Unmarked: an R package for fitting hierarchical models of wild life occurrence and abundance. J Stat Softw. 2011:43:1-23.

Garrote G, Perez de Ayala R, Pereira P, Robles F, Guzman N, Garcia FJ, Iglesias MC, Hervas J, Fajardo I, Simon M, Barroso JL. Estimation of the Iberian lynx (Lynx pardinus) population in the Doana area, SW Spain, using capture-recapture analysis of camera-trapping data. Eur J Wildlife Res. 2011;57:355-62.

Guisan A, Thuiller W. Predicting species distribution: offering more than simple habitat models. Ecol Lett. 2005;8:993-1009.

Hurvich CM, Tsai CL. Bias of the corrected AIC criterion for underfitted regression and time-series models. Biometrika. 1991;78:499-509.

Janecka JE, Munkhtsog B, Jackson RM, Naranbaatar G, Mallon DP, Murphy WJ. Comparison of noninvasive genetic and camera-trapping techniques for surveying snow leopards. J Mammal. 2011;92:771-83.

Li S, McShea WJ, Wang D, Shao L, Shi X. The use of infrared-triggered cameras for surveying phasianids in Sichuan Province, China. Ibis. 2010a;152:299-309.

Li Z, He Y, Yang X, Theakstone WH, Jia W, Pu T, Liu Q, He X, Song B, Zhang N, Wang S, Du J. Changes of the Hailuogou glacier, Mt. Gongga, China, against the background of climate change during the Holocene. Quat Int. 2010b;218:166-75.

Long RA, Donovan TM, MacKay P, Zielinski WJ, Buzas JS. Predicting carnivore occurrence with noninvasive surveys and occupancy modeling. Landsc Ecol. 2011;26:327-40.

Mackenzie DI, Nichols JD, Lachman GB, Droege S, Royle JA, Langtimm CA. Estimating site occupancy rates when detection probabilities are less than one. Ecology. 2002;83:2248-55.

MacKinnon J, Phillipps K, He FQ. A field guide to the birds of China. Oxford: Oxford University Press; 2000.

Marchese C. Biodiversity hotspots: a shortcut for a more complicated concept. Glob Ecol Conserv. 2015;3:297-309.

McGowan PJK, Zhang YY, Zhang ZW. Galliformes - barometers of the state of applied ecology and wildlife conservation in China. J Appl Ecol. 2009:46:524-6.

Niedballa J, Sollmann R, Courtiol A, Wilting A. CamtrapR: an R package for efficient camera trap data management. Methods Ecol Evol. 2016;7:1457-62.

O'Brien TG, Kinnaird MF. A picture is worth a thousand words: the application of camera trapping to the study of birds. Bird Conserv Int. 2008;18:S144-62.

Pollock KH, Nichols JD, Simons TR, Farnsworth GL, Bailey LL, Sauer JR. Large scale wildlife monitoring studies: statistical methods for design and analysis. Environmetrics. 2002;13:105-19.

Shen M, Piao S, Cong N, Zhang G, Janssens IA. Precipitation impacts on vegetation spring phenology on the Tibetan Plateau. Global Change Biol. 2015;21:3647-56

Singh P, Macdonald DW. Populations and activity patterns of clouded leopards and marbled cats in Dampa Tiger Reserve, India. J Mammal. 2017;98:1453-62.

Soldatini C, Albores-Barajas YV, Pellizzi B. Habitat preferences of highaltitude Galliformes in Sagarmatha National Park, Nepal. Ital J Zool. 2010;77:347-53.

Srivastava T, Dutta PK. Snow partridge hopes for a safe home in Arunachal Pradesh. Curr Sci. 2010:98:289.

Sugiura N. Further analysis of data by Akaike's information criterion and finite corrections. Commun Stat Part A Theory Methods. 1978;7:13-26.

Tan CKW, Rocha DG, Clements GR, Brenes-Mora E, Hedges L, Kawanishi K, Mohamad SW, Rayan DM, Bolongon G, Moore J. Habitat use and predicted range for the mainland clouded leopard Neofelis nebulosa in Peninsular Malaysia. Biol Conserv. 2017:206:65-74.

Wookey PA, Aerts R, Bardgett RD, Baptist F, Brathen KA, Cornelissen JHC, Gough L, Hartley IP, Hopkins DW, Lavorel S, Shaver GR. Ecosystem feedbacks and cascade processes: understanding their role in the responses of Arctic and alpine ecosystems to environmental change. Global Change Biol. 2009;15:1153-72

Wu Y, DuBay SG, Colwell RK, Ran J, Lei F. Mobile hotspots and refugia of avian diversity in the mountains of south-west China under past and contemporary global climate change. J Biogeogr. 2017;44:615-26.

Yan Y, Bao X, Liu N. Brooding habitat selection of himalayan snowcock (Tetraogallus himalayensis) in the Yanchiwan Nature Reserve, Gansu Province. Acta Ecol Sin. 2010;30:2270-5 (in Chinese)

Zhang J, Hull V, Ouyang Z, Li R, Connor T, Yang H, Zhang Z, Silet B, Zhang H, Liu $J$. Divergent responses of sympatric species to livestock encroachment at fine spatiotemporal scales. Biol Conserv. 2017;209:119-29.

Zheng GM. A checklist on the classification and distribution of the birds of China. Beijing: Science Press; 2005 (in Chinese).

Zheng GM. Pheasants in China. Beijing: Higher Education Press; 2015 (in Chinese) 